\title{
LOS REFLEJOS DEL PODER: ECOY NARCISO DE CALDERÓN FRENTE A LAS MENINAS DE VELÁZQUEZ
}

\author{
Margaret R. Greer \\ Department of Romance Studies \\ Duke University \\ Durham, NC, 27708-0257 (USA) \\ mgreer@duke.edu
}

[Anuario calderoniano (ISSN: 1888-8046), vol. extra, 1, 2013, pp. 191-211]

Pedro Calderón de la Barca es, a mi parecer, el dramaturgo más consumado de la obra espectacular cortesana europea. Supo combinar todos los ingredientes de tan costosísimos espectáculos para crear unas obras polisémicas, que invitan a la interpretación siguiendo no sólo una, sino todas las líneas nombradas en la presentación de este congreso: como obras filosófico-alegóricas, como estructuras de poder, y en clave política ${ }^{1}$. Eso es lo que propuse al escribir The Play of Power ${ }^{2}$.

Como otros autores de obras cortesanas espectaculares, se sirvió de las historias de la mitología clásica para transmitir el mensaje que in-

${ }^{1}$ Tal polisemia no se observa normalmente en los dramas cortesanos de espectáculo de otros dramaturgos españoles de la época. Tampoco puedo sostener que se dé en todos los espectáculos de corte calderonianos, sin haber estudiado en detalle y en su contexto histórico obras como Amado y aborrecido, Fineza contra fineza y la versión en dos actos de El jardín de Falerina.

2 Greer, 1991. 
teresaba a los reyes, que era, en primer lugar lo que llamo el «texto del poder real», de la gloria y poder de los Habsburgos; o sea, el texto como "estructura de poder». En segundo lugar, aprovechando los vicios y debilidades muy «humanos» de los dioses como un arma de doble filo, lograba transmitir a cada espectador o lector una lección filosófico-alegórica con relevancia más o menos universal; una historia que denomino «el texto individual». $Y$ en tercer lugar, incorporaba a la obra lo que llamo «el texto político»: un mensaje, discretamente velado, sobre algún tema relevante a la política y la práctica del rey, que era su espectador principal.

Al escribir un libro sobre estos dramas, apenas toqué la obra calderoniana que primero me atrajo al género, Eco y Narciso. Vuelvo a ella ahora como parte de un estudio de la tragedia en la primera modernidad. Esta obra es una tragedia en mi opinión, a pesar de la transformación final de los protagonistas ${ }^{3}$. Lo que presento hoy es, por supuesto, sólo un esbozo de lo que será el capítulo final del libro.

Eco y Narciso fue representada en el palacio del Buen Retiro en julio de 1661, para celebrar el décimo cumpleaños de la princesa Margarita, figura central de la obra maestra de Velázquez, Las meninas - $\mathrm{O}$ La familia real [Figura 1], como fue llamada originalmente- La obra sería repetida en diciembre del mismo año, aunque sin el mismo despliegue espectacular ${ }^{4}$, y de nuevo en 1682 y 1692.

No tenemos una descripción completa de esta representación, pero sabemos por las descripciones de otras fiestas cortesanas que sí han sobrevivido que lo que llamo el texto de poder real fue transmitido por cuatro elementos: 1) el coste del festival ${ }^{5}$; 2) la entrada ceremoniosa al teatro real, con el resto de los espectadores ya ubicados en su lugar para observar la entrada de la familia real; 3) el arreglo jerárquico del teatro, con los reales espectadores sentados en el emplazamiento más ideal para ver la obra y apreciar la escenografía en perspectiva, y los

${ }^{3}$ Ver el buen análisis de la obra de O’Connor, 1988, pp. 87-117.

4 Stein, 1993, p. 168.

5 En 1635, por ejemplo, cuando se estrenó la primera comedia calderoniana de esta clase, El mayor encanto, Amor, en el mismo año en que se reanudó la guerra con Francia, se dijo en las Noticias de Madrid que tales fiestas no eran sólo diversiones, sino también "ostentación para que el Cardenal Richelieu, nuestro amigo, sepa que aún hay dinero en el mundo que gastar y con que castigar a su Rey». Citado en Deleito y Piñuela, 1935, p. 215. 
otros espectadores colocados donde podían ver la obra, apreciar la presencia real y observar a sus monarcas mientras estos contemplaban el espectáculo $;$ y 4) la loa con que empezaría la representación, un minidrama muy espectacular que siempre nombra y elogia a los espectadores reales.

El texto que nos queda de Eco y Narciso no ayuda mucho a saber cómo funcionó el texto de poder real en esta fiesta. Fue publicado en la Cuarta parte de Calderón de 1672, enmendado y corregido con la adición de unos 200 versos en la segunda impresión de 1674, pero no es el mismo que se representó en el Coliseo del Buen Retiro, sino una versión simplificada para las posteriores repeticiones, sin el mismo despliegue espectacular, destinada a su puesta en escena en corrales públicos o para representaciones particulares de palacio. No incluye la loa ni contiene descripciones de los múltiples cambios de escenario típicos de estas obras 7 . No obstante, sabemos que el vínculo entre los espectadores reales y los dioses no se desvanece al pasar de la loa al drama central, porque Calderón sitúa a la princesa Margarita en el centro del tablado. No físicamente, por supuesto, sino reflejada en la ninfa Eco: la fiesta teatral celebra el cumpleaños de la princesa Margarita Teresa, y el drama se inicia con una celebración del cumpleaños de Eco.

La ninfa Eco de la historia de Ovidio es en la obra calderoniana una pastora joven, bella y rica, objeto del deseo de todos los pastores en una Arcadia pastoril. Pero esta Arcadia, al contrario de lo que afir-

${ }^{6}$ Señala S. Orgel al comentar el mismo tipo de espectáculo en Inglaterra que lo que veían los espectadores no era sólo el drama sobre el tablado, sino el más complejo espectáculo de observar al rey contemplar el drama. Añade Orgel que «su reacción no habría sido provocada simplemente por el drama, sino también por la relación entre el drama y su audiencia primaria, el espectador real» (traducción mía). Ver Orgel, 1975, p. 9.

7 Sin embargo, se puede inferir del texto de 1674 el uso de varios escenarios: una primera escena, de bosque; tal vez otra de monte y de la cueva de Liríope y Narciso; una referencia a una escena en un templo, que parece haber sido eliminada de la primera jornada pero cuyo rastro permanece en la primera acotación de la jornada segunda: «Salen todos los del Templo que acabaron la primera jornada»; la fuente en que se ve y "muere» Narciso; y una descripción textual de la transformación final. Las acotaciones en las ediciones de Aubrun y de Valbuena Briones no se derivan de las de 1672 y 1674. 
ma Antonio Cascardi, no es un espacio fuera del tiempo ${ }^{8}$. Cuando los dos pastores cortesanos, Febo y Silvio, invitan a todos a unirse a la celebración, celebran a la pastora de una manera sorprendente: le recuerdan su propia mortalidad. En palabras de Febo:
Pésames viene a daros mi tristeza de que la rara y singular belleza de Eco, desengañada de que ha sido inmortal, hoy un círculo ha cumplido de sus años, que, aunque de dichas llenos, cada año es una gracia menos 9 .

Febo reitera su deseo de que ella fuera inmortal, de que la muerte nunca cambiara las rosas de su cara; pero luego interviene Bato. En esta obra palaciega, el gracioso, como en las comedias de corral, es la voz de los intereses materiales y villanos, en contra de la retórica elevada de los dioses y pastores idealizados. Luciana Gentilli, en su excelente libro - publicado el mismo año que el mío y en el que llega a conclusiones similares sobre las obras cortesanas de Calderón-, describe bien la función del gracioso: «La rotura umoristica dell'illusione scenica è una prerogativa del "gracioso". Con le sue burle "innocenti" egli irride alla credulità della platea, ristabilendo un circuito tra vita e creazione drammatica» ${ }^{10}$. Al romper la ilusión escénica, en esta obra el gracioso introduce la muerte en el circuito entre la vida y la creación dramática. Según Bato, es mejor morir joven que volverse vieja. Dice:

Mi lengua no te aconseja vivir tanto, que es error, pues morir moza es mejor que no llegar a ser vieja ${ }^{11}$.

Hasta años relativamente recientes, estas fiestas cortesanas calderonianas fueron olvidadas o condenadas por los críticos como obras de un solipsismo escapista y de adulación vacía de la familia real. Han

\footnotetext{
8 Cascardi, 1984, pp. 130, 150. Ver también Larson, 1987.

${ }^{9}$ Calderón de la Barca, Eco y Narciso, p. 4.

10 Gentilli, 1991, p. 240.

11 Calderón de la Barca, Eco y Narciso, p. 6.
} 
sido caracterizadas así por Cascardi y por Sebastian Neumeister tanto en su sustancioso libro sobre ellas, de 1978, como en la versión revisada en español ${ }^{12}$. Neumeister ve en las de los años de Felipe IV y de Carlos II «una egolatría narcisista casi sin referencias al exterior» ${ }^{13}$. Gentilli, en contraste, critica la perspectiva de Neumeister, proponiendo que tales obras no son una mera apología del poder absoluto, sino un modo de prevenir al soberano y de reflexionar sobre problemas del momento ${ }^{14}$. Apoyándose en citas bien seleccionadas de Saavedra Fajardo, de Juan de Zabaleta, Bances Candamo y otros comentaristas contemporáneos del dramaturgo, Gentilli sostiene que Calderón empleaba las fábulas mitológicas para «dorar la píldora», pues presentaba dentro de agradables cuentos ciertas verdades amargas cuyo pleno significado sería captado sólo por una élite instruida capaz de entender$1 \mathrm{o}^{15}$. Las evocaciones del tiempo en Eco y Narciso demuestran que, al contrario de la concepción solipsista de las obras mitológicas espectaculares, Calderón utiliza la figura de Eco para mostrar ante la princesa Margarita y su familia una imagen de su propia imperfección y fragilidad, de una existencia parecida a lo que Heidegger denominaría el «ser para la muerte», una imagen consonante con el desengaño barroco.

El paralelismo entre las jóvenes mítica y real que cumplen años es sólo el primero de varios casos de reflejo y de dobles en la obra. El más acusado - hasta llegar a ser irritante- es el reflejo que hay entre Febo y Silvio, el par de "pastores» enamorados de Eco, quien no corresponde a ninguno de los dos. Son las dos caras de la retórica del amor cortés, que se diferencian sólo en la proyección de su amor frustrado. Silvio, más agresivo, lo proyecta hacia afuera e intenta matar a Narciso, celoso de que Eco se haya enamorado del bello joven. Febo, más masoquista, intenta proteger a Narciso porque Eco lo quiere.

Esta lectura de las dos caras del amor cortés nos lleva a la segunda línea interpretativa, la filosófico-alegórica. A la sombra de la amplia influencia de la descripción freudiana de Narciso como modelo representativo de una etapa del desarrollo humano de autoabsorción

12 Cascardi, 1984, pp. 130, 150; Neumeister, 1978, pp. 268-283; Neumeister, 2000, pp. 296-302.

13 Neumeister, 2000, p. 301.

14 Gentilli, 1991, pp. 16-18.

15 Gentilli, 1991, pp. 32-40. 
que se vuelve patológica en los que no la superan, la obra invita a una lectura psicoanalítica. Como dice Antonio Regalado, en esta obra, el discurso del arte literario calderoniano prefigura el discurso psicoanalítico. Lo hace, según Regalado, al representar el nacimiento del sujeto auto-consciente y deseante, que reconoce que lo que siente es «la ilusoria superficie de un reflejo", pero aun así no puede renunciar a ello. Tal sujeto, dice el crítico, «invierte los términos del bimundo platónico-cristiano, a saber, que el otro mundo es mera imagen de éste, de nuestro deseo» ${ }^{16}$. Reconocer esto no significa olvidar que, desde Ovidio hasta el Renacimiento y el Barroco, la historia de Narciso solía leerse como una advertencia en contra de la vanagloria [Figura 2] ${ }^{17}$. La obra de Calderón sirve como una suerte de bisagra que posibilita el entendimiento de la historia ya hacia la moralidad tradicional, ya hacia la psicología del sujeto moderno. Havelock Ellis cita el tratamiento calderoniano del personaje en Eco y Narciso precisamente como «la transición entre la perspectiva clásica y la moderna de la figura de Narciso» ${ }^{18}$.

Eco, menos importante en la historia de Ovidio, es tan central en el drama de Calderón como Narciso.Y es también su reflejo invertido, como Febo lo es de Silvio. Mientras que Narciso muere a causa de una absorción total con respecto a su propia imagen, ahogado en una condición de narcisismo primario que bloquea su capacidad de comprometerse en el amor a otra persona, Eco, como dice su nombre, es una voz que será reducida a repetir el discurso del orden social, una cáscara vacía que se disuelve en el aire cuando pierde la adoración del Otro. Aunque desdeña tanto el cortejo de Febo como el de Silvio, le preguntará al pastor tímido Anteo por qué no añade su voz al coro que la festeja. Anteo, que no puede verbalizar su amor por ella, va a cazar un obsequio y vuelve con el «monstruo» que habita en el monte de Arcadia, un ser humano vestido de pieles: Liríope, la

16 Regalado, 1995, p. 300.

17 Neumeister, aunque reconoce que los objetivos de los autos y las obras cortesanas son diferentes, lee Eco y Narciso en términos cristológicos, como una "pieza didáctica teológica», viendo en Narciso un Cristo fracasado en contraste con el Aquiles calderoniano de El monstruo de los jardines, en quien ve una figura de la muerte y resurrección de Cristo. Gentilli califica esta lectura como una «decodificazioni perlomeno discutibili». Gentilli, 1991, p. 18; Neumeister, 2000, pp. 189-222.

18 Ellis, 1928, vol. 7, p. 349. 
madre de Narciso, que ha salido de caza también, en busca de comida para el hijo que ha dejado en su cueva.

Liríope es, como dijo Everett Hesse, una «madre terrible», cuyo proceder explica la patología de su hijo; una mujer esquiva raptada por el hijo del viento, Céfiro, convertida en una figura materna todoenvolvente que ocupa aquí el lugar del padre tiránico en otras obras calderonianas. El profeta Tiresias, quien la había cobijado, antes de morir le dijo a Liríope que daría a luz a un hijo muy bello. Añadió que a este hijo "una voz y una hermosura / solicitarán su fin, amando y aborreciendo" y que, por eso, debía preservarle de ver y oír. El Narciso de Calderón, por lo tanto, es otra variante de la figura de Segismundo de La vida es sueño, encarcelado por su progenitor para evitar que se cumpla un hado fatal que el hijo o sufriría o provocaría. Con la diferencia de que la cárcel de Narciso no es una torre, el edificio militar fálico del padre real de Segismundo, sino una cueva, a la vez el cobijo primigenio del hombre y el símbolo uterino de la primera estancia de cada ser humano.

El canto de Eco y la gente de Arcadia inducen a Narciso a dejar ese espacio. Con esto, Calderón introduce el tema de la voz, del habla como el vínculo fundamental del orden social, y de los problemas de la comunicación humana, agraviados en este joven que no sabe cómo viven los hombres. Al ver a Eco, dice que su voz y su imagen han encendido un fuego en sus ojos y en su corazón, nombrando así el tema de la vista y de su poder. Luego sigue una especie de baile, un bello pas de deux de la atracción sexual adolescente. Lo que Narciso llama su «instinto natural» los atrae mutuamente, mientras que el hado de Tiresias repetido por Liríope le hace alejarse de Eco. Lo que Eco canta al perseguirle prefigura su destino final y las limitaciones del discurso humano: «Sólo el silencio testigo / ha de ser de mi tormento. $/ \mathrm{Y}$ aun no cabe lo que siento / en todo lo que no digo» ${ }^{19}$. Pero es la intervención de Liríope la que provoca el desastre. La madre recurre al empleo del veneno y la magia aprendida de Tiresias para dejar sin voz a Eco. De esta manera, reduce a la ninfa a lo que en un sentido siempre ha sido: nada más que el eco de la voz de otros. En este estado, es incapaz de advertir a Narciso de que la belleza silenciosa que ve en la fuente en que se mira es su propia imagen.

${ }^{19}$ Calderón de la Barca, Eco y Narciso, pp. 26-27. 
En el Narciso de Calderón, podemos apreciar la intuición del dramaturgo del Barroco de la naturaleza del sujeto escindido descrito por Lacan, que sólo viene a conocerse en la alienación, en su imagen reflejada ${ }^{20}$. Otros aspectos del drama invitan a una lectura según la teoría de Julia Kristeva de la abyección materna, del miedo de ser absorto de nuevo dentro del espacio indiviso «moi / pas moi» en la ausencia del mandato paterno que efectúa la separación del bebé de la madre y la incorporación del niño en el orden simbólico ${ }^{21}$. Es una separación que no ha ocurrido en el caso de Narciso. A la vez, el malogro de la unión de Eco y Narciso es, como en otras tragedias calderonianas, el resultado de una deficiencia en el lenguaje, la ambigüedad del significante que permite el malentendido del dictado del hado.

El vidente ciego Tiresias que pronuncia el hado es en otros mitos clásicos un ser transexual, un hombre que fue transformado en mujer durante siete años. No lo es en el drama de Calderón. Aquí, con la excepción de Narciso, ambos sexos se comportan de acuerdo con los papeles tradicionales en el origen de la tragedia. El que una mujer como Liríope, de dureza diamantina, se mostrara esquiva ante el ardor amoroso de Céfiro era considerado antinatural en el orden sexual de la primera modernidad española. Pero, por otro lado, este personaje mantenía el silencio virginal que dictaba la sociedad, respondiendo sólo con el lenguaje corporal de sus mejillas ruborizadas:

A entender me dio su amor cortésmente, a que el carmín respondió de mis mejillas, parlero no, mudo $s i^{22}$.

Céfiro, apoyado por su padre, el viento, responde con una agresión sexual violenta, como relata Liríope:

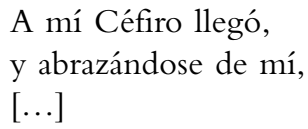

${ }^{20}$ En el caso de Eco, aún más que en el de Narciso, la voz del deseo es el deseo del Otro. Ver también el análisis de Regalado, 1995.

${ }^{21}$ Kristeva, 1980, pp. 13-21.

22 Calderón de la Barca, Eco y Narciso, p. 18. 


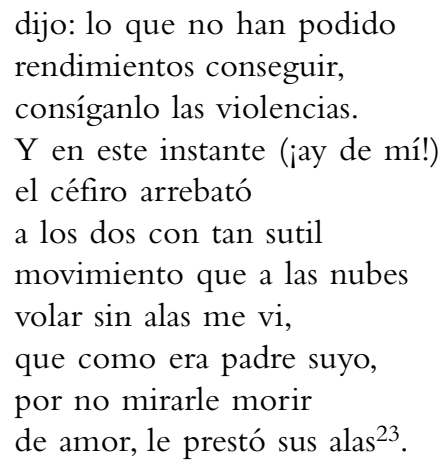

En la metamorfosis que concluye el drama, Eco se disuelve en el aire, volviendo así al espacio de la agresión sexual violenta de Céfiro y de su padre, el viento. Y Narciso, vuelto una flor, se arraiga en la tierra, la tierra material asignada a la mujer, de la cual, en otro sentido, no se ha apartado nunca.

Las transformaciones milagrosas, que aseguran el final feliz obligatorio en una obra palaciega, se describen de este modo en la penúltima acotación:

Teniendo Febo asida a Eco, y Silvio a Narciso, vuela Eco a lo alto, y cae como muerto Narciso en el tablado. Suena ruido de terremoto, obscuréscese el teatro, $\gamma$, cesando, sale de la tierra una flor que imite a la de Narciso, y oculte el cuerpo que cayó en el tablado ${ }^{24}$.

Pero el gracioso Bato las desmiente, diciendo: «Y habrá bobos que lo crean» ${ }^{25}$. Continúa, concluyendo con la disculpa del dramaturgo:

Mas, sea cierto o no cierto, tal cual la fábula es

23 Calderón de la Barca, Eco y Narciso, p. 18.

${ }^{24}$ Calderón de la Barca, Eco y Narciso, p. 73. Esta acotación aparece en la Cuarta parte de Vera Tassis y todas las ediciones subsiguientes, pero no en los textos de 1672 y 1674, aunque se puede deducir la misma tramoya del final del diálogo en sí.

25 Calderón de la Barca, Eco y Narciso, p. 74. Como Gentilli y O'Connor señalan, otro Bato calderoniano inserta el mismo comentario escéptico en un momento culminante de Las fortunas de Andrómeda y Perseo.Ver Gentilli, 1991, p. 240; O'Connor, 1988, p. 114. 
esta de Narciso y Eco.

Perdonad las muchas faltas

del que, a vuestras plantas puesto,

siempre acuerda la disculpa

de que yerra obedeciendo ${ }^{26}$.

¿Por qué celebrar con tal drama el décimo cumpleaños de la infanta Margarita? ¿Qué tipo de texto político podemos recuperar de este espectáculo de 1661? Algunas lecturas críticas que se han hecho de Las meninas de Velázquez sugieren una respuesta.

Javier Portús Pérez resume «una densa red de significados» que contiene el cuadro:

Existe, por ejemplo, una reflexión sobre la identidad regia de la infanta, lo que, por extensión llena el cuadro de contenido político. Pero también hay varias referencias importantes de carácter histórico-artístico, que se encarnan en el propio pintor o en los cuadros que cuelgan de la pared del fondo; y la presencia del espejo convierte al cuadro en una reflexión sobre el acto de ver y hace que el espectador se pregunte sobre las leyes de la representación, sobre los límites entre pintura y realidad y sobre su propio papel dentro del cuadro ${ }^{27}$.

Michel Foucault, en Las palabras y las cosas, analiza el juego de los espacios y las líneas de visión en la captura de la mirada y concluye que es «la representación en su forma pura», la representación de un «vacío esencial: la desaparición necesaria de lo que la fundamenta (de aquel a quien se asemeja y de aquel a cuyos ojos no es sino semejanza)» ${ }^{28}$. En suma, la desaparición del sujeto. Alban Forcione relaciona esta lectura de Las meninas a la vez con la subjetividad moderna y con la filosofía política de la primera modernidad. Teniendo en cuenta que el rey y la reina están presentes sólo como una imagen borrosa, espectral, en el espejo, Forcione concluye que el cuadro es una escena de la «interioridad inasequible de la individualidad» que revela la nada sobre la cual se asienta la majestad real29. Pierre-Gilles Guéguen añade una lectura lacaniana que se centra en la familia real, congela-

\footnotetext{
26 Calderón de la Barca, Eco y Narciso, p. 74.

27 Portús Pérez, 2007, pp. 338, 339.

${ }^{28}$ Foucault, 2005, p. 25.

${ }^{29}$ Forcione, 2009, p. 4.
} 
da en el tiempo, y en la sexualidad escondida de la princesa, que contiene la clave problemática de la continuación de su reinado ${ }^{30}$.Y José Luis Colomer nos da testimonio del uso análogo del arte para fines político-dinásticos en las negociaciones para el matrimonio de María Teresa con Luis XIV. En 1657, la infanta le envió a su tía, la reina francesa Ana de Austria, un pequeño retrato de oro de porcelana en el cual estaba pintado Luis XIV por un lado y por el otro, María Teresa con una imagen de Felipe IV sobre su pecho. Colomer explica que

según un uso frecuente en la época, las dos efigies formaban el anverso y el reverso de una misma joya que no sólo reunía a los posibles cónyuges, sino que mediante el procedimiento del retrato dentro del retrato [...] servía también para resaltar la idea de sucesión dinástica ${ }^{31}$.

Y para la celebración del matrimonio en la Isla de los Faisanes en 1659, María Teresa le llevó a Ana otra joya parecida: una joya portarretratos con nueve diamantes grandes y cuatro retratos en el anverso: Felipe IV, Mariana de Austria, Felipe Próspero y la infanta Margarita $^{32}$.

Como ya queda dicho, es impresionante el número de dobles y de reflejos en Eco y Narciso, desde el reflejo inicial entre Eco y la infanta Margarita, hasta los reflejos invertidos de Eco y Narciso y Febo y Silvio y el reflejo fatal de Narciso en la fuente. Nos involucran en la obra, de manera análoga a la fascinación crítica con las líneas de visión y de reflejo en Las meninas entre el cuadro, el espejo y los reyes reflejados en él. Joel Snyder arguye que la imagen en el espejo no es sólo un reflejo corpóreo del rey y la reina delante de la escena del cuadro, sino también de una imagen conceptual, ejemplar, como el espejo en la empresa 2 de Saavedra Fajardo, Ad Omnia [Figura 3] ${ }^{33}$. El espejo manifiesta tanto la imagen natural de los reyes como la imagen ideal de una perfecta majestad en el espejo ejemplar, que gobierna a todos los demás en la escena. Y la imagen de Margarita es también doble: de su ser físico, el reflejo natural de sus padres, y de la

30 Guéguen, 1989, pp. 56-57.

31 Colomer, 2003, p. 77.

32 Colomer, 2003, p. 76.

33 Saavedra Fajardo, Idea de un príncipe cristiano representada en cien empresas, p. 8. 
criatura que en el cuadro se convierte en el «espejo de una princesa» ${ }^{34}$.

J. A. Emmens y Santiago Sebastián también relacionan el cuadro con la representación emblemática de monarcas, incluyendo tanto la empresa 2 como la 28 de Saavedra Fajardo [Figura 4] ${ }^{35}$. La serpiente enroscada en el cetro simboliza la prudencia real, dice Emmens; y la adición de los espejos laterales extiende esa visión prudente sobre el pasado, el presente y el futuro, de tal manera que el grabado se refiere a la generación pasada, presente y futura de los candidatos reales de la casa de Habsburgo, dentro y fuera de la tela pintada ${ }^{36}$. Para Sebastián, el pasado es evocado por el atelier de Velázquez en el cuarto del príncipe Baltasar Carlos, muerto en 1645; el presente en la forma de la infanta María Teresa - heredera hasta el nacimiento de Felipe Próspero-, que Sebastián imagina al lado del rey y la reina porque venía con frecuencia a ver a Velázquez pintar; y el futuro es representado por la infanta Margarita, a menos que naciera otro heredero varón ${ }^{37}$.

El retrato del príncipe Felipe Próspero [Figura 5], como niño tierno y frágil, adornado con amuletos para protegerle contra el mal de ojo, nos comunica el problema. Al igual que varios hermanos anteriores, Felipe Próspero moriría cuatro meses después de la representación de Eco y Narciso, en noviembre de 1661, pocos días antes del nacimiento de Carlos II. Carlos sobrevivió hasta coronarse rey, pero con tales limitaciones fisicas y mentales que no pudo tener descendencia ni gobernar más que nominalmente. Sin un heredero masculino sano y maduro, el peligro para los Habsburgos de Madrid era que un consorte real extranjero reclamara el trono a la muerte de Felipe IV - o, más tarde, de la de Carlos II-. En una edad que no comprendía los peligros genéticos de la endogamia, pero sabía de memoria la tacha del pecado original y los diez mandamientos, Felipe IV sentía que la debilidad y mortandad de sus hijos legítimos, comparada con la salud de sus muchos hijos espurios, era un castigo divino por sus amoríos extramaritales.

El bastardo real más distinguido en 1661 fue don Juan José de Austria. Don Juan José había propuesto como solución a la falta de

\footnotetext{
34 Snyder, 1985, pp. 563-564.

35 Saavedra Fajardo, Idea de un príncipe cristiano representada en cien empresas, p. 186.

36 Emmens, 1995; Sebastián, 1989.

37 Sebastián, 1989, pp. 203-204.
} 
un heredero masculino que se casara él con su media-hermana María Teresa. Después del nacimiento de Felipe Próspero, ella fue casada con el futuro Luis XIV, con la condición de que renunciara a cualquier derecho futuro al trono español. Luego, don Juan José se valió de una joya pintada como las descritas por Colomer para sugerir discretamente otra solución matrimonial. La joya era una miniatura que él mismo había pintado de los amores entre los hermanos divinos, Júpiter y Juno, pero con su propio rostro y el de la infanta Margarita ${ }^{38}$. Al ver la miniatura, Felipe IV, ya muy enfermo, le dio la espalda y no quiso verle de nuevo antes de su muerte en 1665. La princesa se casaría con Leopoldo I de Austria, a quien había sido prometida al nacer; y don Juan José llegaría al poder no como rey ni consorte, sino como primer ministro en 1677, por medio del primer golpe de estado en la historia moderna de España. Los matrimonios extranjeros de las dos princesas tuvieron, de hecho, el efecto temido: el de avivar los argumentos rivales de la casa Borbona francesa y la Habsburgo austriaca sobre el trono español; rivalidad que desencadenó la Guerra de Sucesión en 1700 y no se aplacó hasta 1713, cuando el nieto de María Teresa y Luis XIV subió al trono como Felipe V.

Algunos moralistas de la época de Calderón asignaban parte de la culpa de la debilidad de los herederos reales a la restricción de los infantes al mundo femenino de la reina y sus damas ${ }^{39}$. Y Valbuena Prat leyó en Eco y Narciso "un adivinador acierto psicológico» calderoniano en culpar de la tragedia de Narciso a una educación equivocada, en dependencia única con la madre ${ }^{40}$. Al mismo nivel pragmático de la discreta lección política para el rey y la reina que se ven reflejados en el espejo de Velázquez, podríamos ver también en la obra de Calderón una advertencia del peligro de criar a los infantes en el ámbito reducido del palacio, abrumados por mimos y halagos y poco preparados para el mundo de obligaciones que deberán afrontar. Para una princesa de 10 años, un recordatorio no tan sutil, pese a su centralidad y las numerosas atenciones que las meninas le dispensaban en la corte: que ella, al igual que todos los espectadores de la obra, también era una criatura mortal. De hecho, moriría en 1673, sólo 12 años más

38 Maura Gamazo, 1911, vol. I, pp. 192-193.

39 Maura Gamazo, 1911, vol. I, pp. 85-86, 290-291, 296.

40 Valbuena Prat, 1931, p. 12. 
adelante. Dudo que hubiera secundado las palabras de Bato sobre los beneficios de morir moza cuando falleció a los 26 años, habiendo dado a luz a seis hijos, de los cuales sólo una, María Antonia, llegó a alcanzar la madurez. 


\section{Bibliografía}

Calderón de la BARCA, P., Comedias mitológicas: Eco y Narciso, ed. Á.Valbuena Prat, Madrid, Compañía Iberoamericana de Publicaciones, 1931, pp. 714.

- Eco y Narciso, en la Cuarta parte de Comedias, Madrid, Joseph Fernández de Buendia, 1672, fols. 50v-89r; y Madrid, Bernardo de Hervada, 1674, fols. 25v-46r; edición facsímil de D. W. Cruickshank y J. E.Varey, London, Gregg International Publishers Limited / Támesis Books Limited, 1973, vols. 10 y 11.

- Eco y Narciso, ed. Á.Valbuena Briones, en Obras completas, vol. I, Comedias, Madrid, Aguilar, 1959, pp. 1957-1990.

- Eco y Narciso, ed. Ch. Aubrun, Paris, Centre de Recherches de l'Institut d'Études Hispaniques, 1963.

Cascardi, A., The Limits of Illusion: A Critical Study of Calderón, Cambridge, Cambridge University Press, 1984.

Colomer, J. L., «Paz política, rivalidad suntuaria. Francia y España en la isla de los Faisanes», en Arte y diplomacia de la Monarquía Hispánica en el siglo XVII, ed. J. L. Colomer, Madrid, Fernando Villaverde, 2003, pp. 60-88.

Deleito y Piñuela, J., El rey se divierte, Madrid, Espasa Calpe, 1935.

Elus, H., Studies in the Psychology of Sex, Philadelphia, Davis, 1928, vol. 7, pp. 347-365.

Emmens, J. A., "Las meninas de Velázquez: espejo de príncipes para Felipe IV», en Otras meninas, ed. F. Marías, Madrid, Siruela, 1995, pp. 43-66.

Forcione, A., Majesty and Humanity: Kings and Their Doubles in the Political Drama of the Spanish Golden Age, New Haven, Yale University Press, 2009.

Foucault, M., Las palabras y las cosas, México / Buenos Aires, Siglo xxi Editores, 2005.

Gentilli, L., Mito e spettacolo nel teatro cortigiano di Calderón de la Barca: Fortunas de Andrómeda y Perseo, Roma, Bulzoni Editore, 1991.

Greer, M., The Play of Power: Mythological Court Dramas of Pedro Calderón de la Barca, Princeton, Princeton University Press, 1991.

GuÉGuen, P., «Foucault and Lacan on Velázquez: The Status of the Subject of Representation", trad. H. W. Sullivan, Newsletter of the Freudian Field, 3, 1989, pp. 51-57.

Kristeva, J., Pouvoirs de l'horreur: Essai sur l'abjection, Paris, Éditions du Seuil, 1980.

Larson, C., «Playing for Time and Playing with Time in Calderón's Eco y Narciso", Bulletin of the Comediantes, 39, 1987, pp. 115-126.

Maura Gamazo, G., Carlos II y su corte. Ensayo de reconstrucción biográfica, Madrid, F. Beltran, 1911, 2 vols. 
Neumeister, S., Mito clásico y ostentación: los dramas mitológicos de Calderón, trans. E. Reichenberger y J. L. Milán, Kassel, Reichenberger, 2000. [Versión original: Mythos und Repräsentation: Die mythologischen Festspiele Calderóns, München, Wilhelm Fink Verlag, 1978.]

O'Connor, T. A., Myth and Mythology in the Theater of Pedro Calderón de la Barca, Austin, Texas, Trinity University Press, 1988.

Orgel, S., The Illusion of Power: Political Theater in the English Renaissance, Berkeley, University of California Press, 1975.

Portús Pérez, J. (ed.), Fábulas de Velázquez: mitología e historia sagrada en el Siglo de Oro, Madrid, Museo Nacional del Prado, 2007.

Regalado, A., Calderón: los orígenes de la modernidad en la España del Siglo de Oro, Barcelona, Destino, 1995, vol. 2, pp. 289-315.

SaAVedra Fajardo, D., Idea de un príncipe cristiano representada en cien empresas, Monaco, [s. n.], 1640, Milano, [s. n], 1640. Reproducción del ejemplar de la BNE R/3470, pp. 8, 186.

SEbastián, S., «Nueva lectura de Las meninas: un retrato emblemático y pedagógico», Lecturas de Historia del Arte Ephialte, 1, 1989, pp. 189-207.

SNyder, J., "Las meninas" and the Mirror of the Prince», Critical Inquiry, 11, 4, 1985, pp. 539-572. 


\section{ILUSTRACIONES}

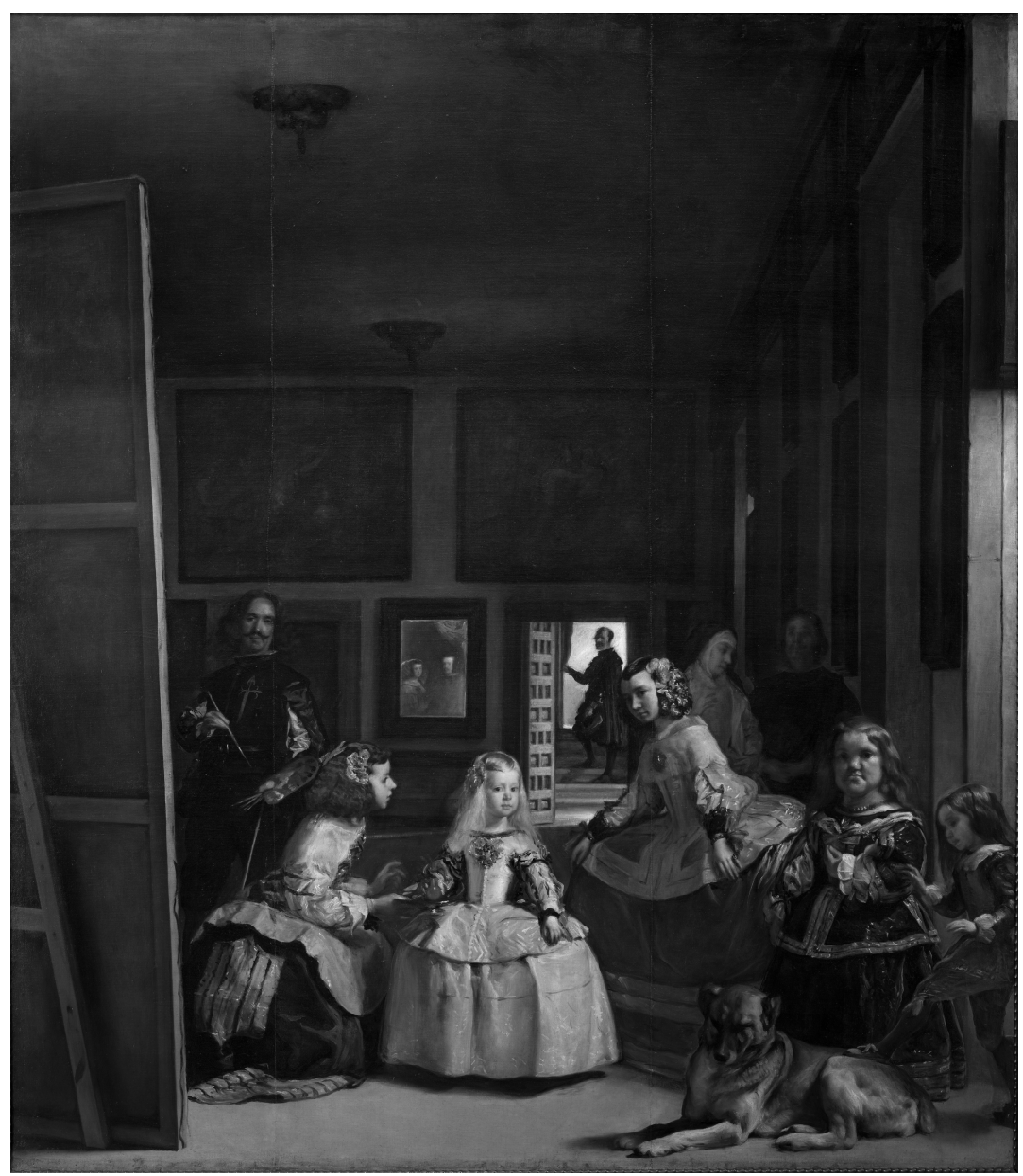

Figura 1: Diego de Velázquez, Las Meninas, 1656.

(C) Museo del Prado, Madrid 


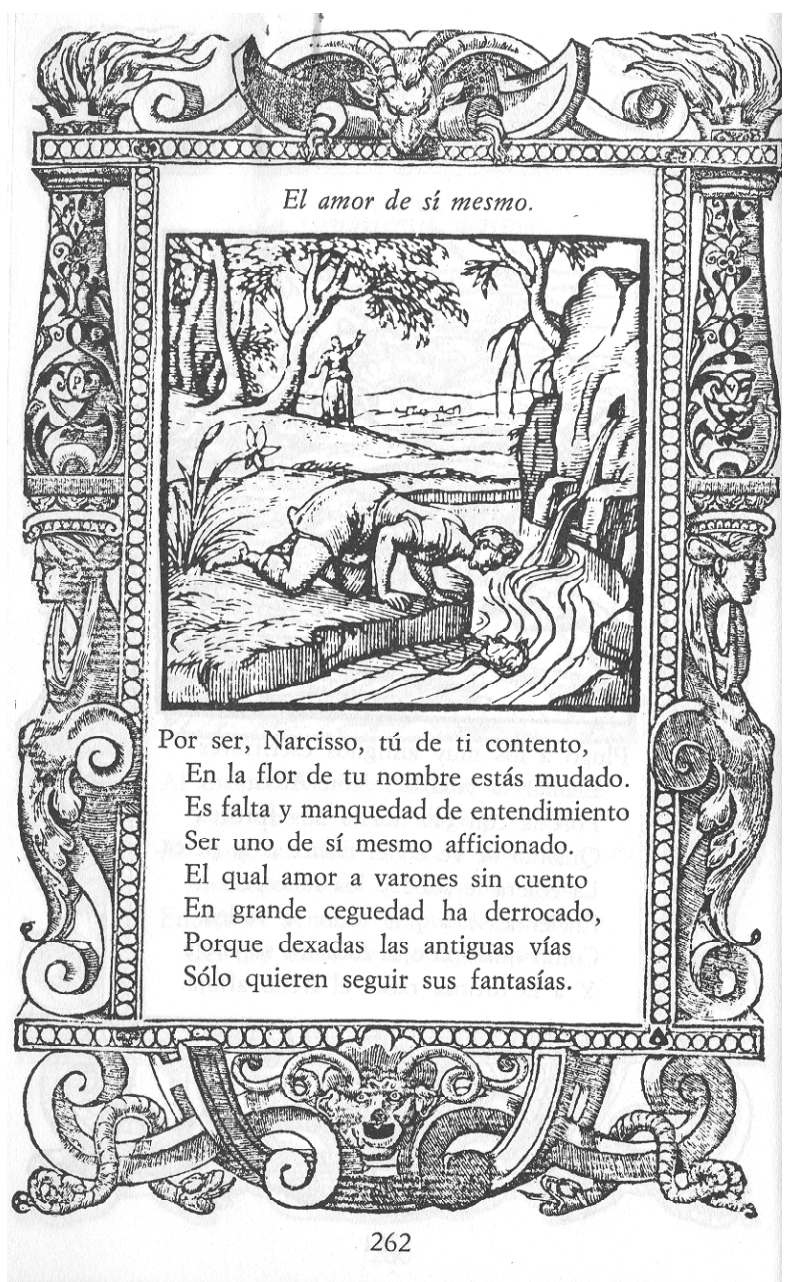

Figura 2: Andrea Alciati, «El amor de sí mesmo», Emblemas 


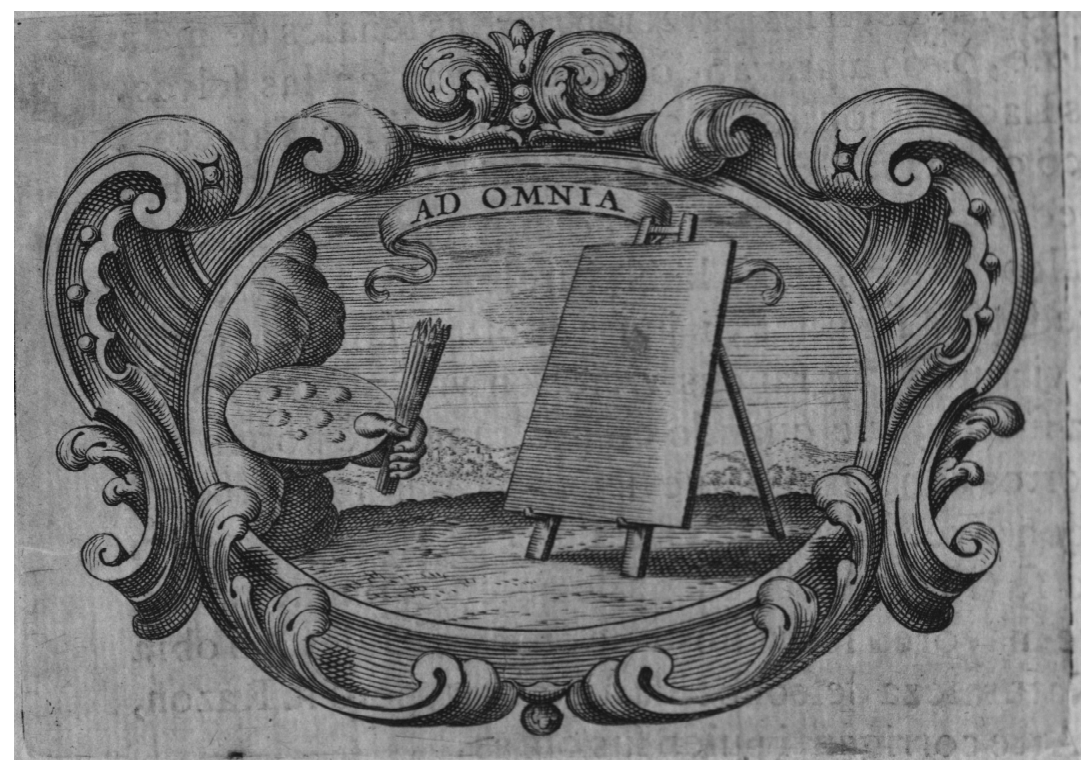

Figura 3: Diego Saavedra Fajardo, Emblema 2, Ad Omnia, de Empresas políticas. Idea de un príncipe político-cristiano 


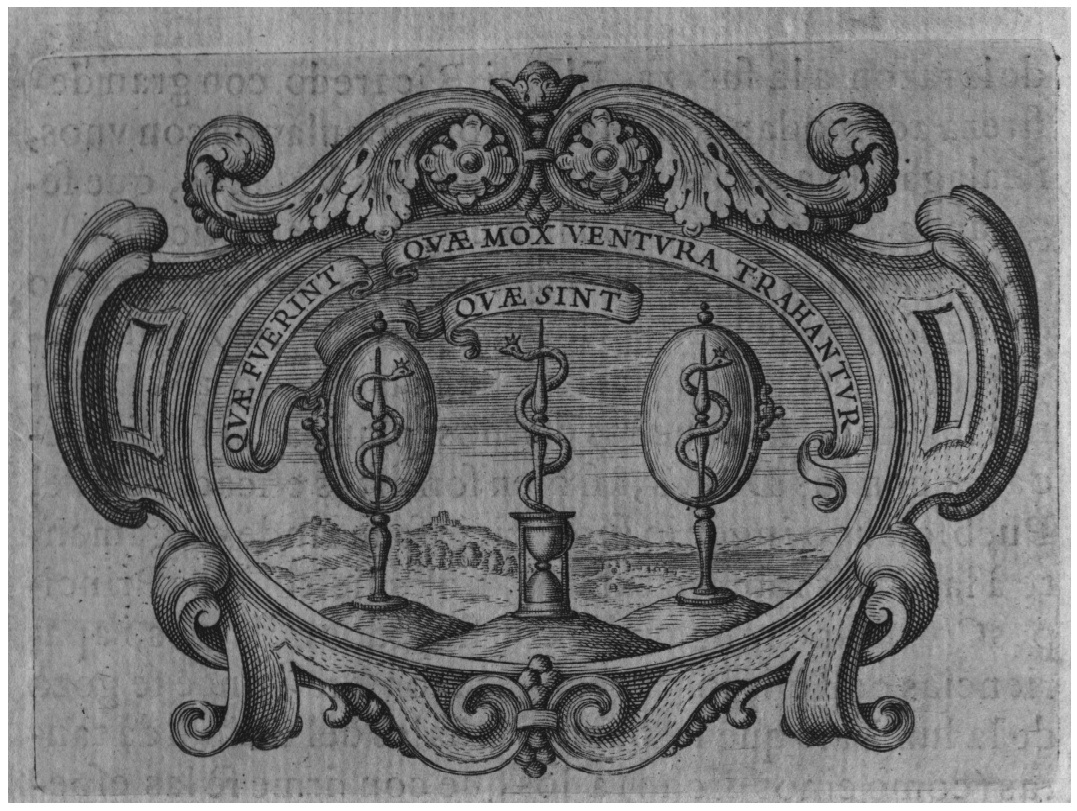

Figura 4: Diego Saavedra Fajardo, Emblema 28 de Empresas políticas. Idea de un príncipe político-cristiano 


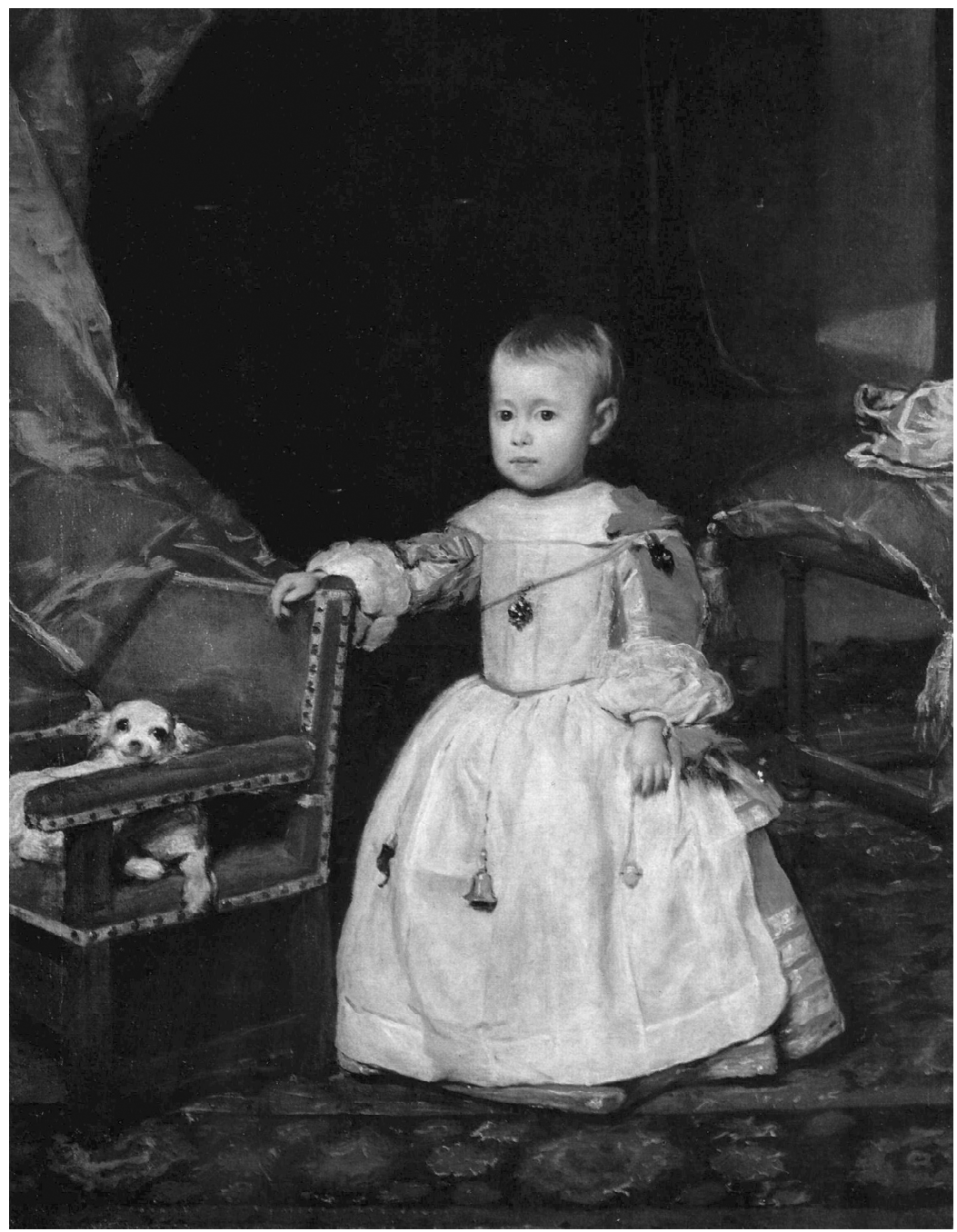

Figura 5: Diego de Velázquez: El infante Felipe Próspero, (C) Kunsthistorisches Museum, Viena, Austria 